\title{
A OBSERVAÇÃO REFLEXIVA NA PRÁTICA PEDAGÓGICA DOS PROFESSORES EM FORMAÇÃO INICIAL CONSTITUINTE DA TRANSPOSIÇÃO DIDÁTICA DOS SABERES A ENSINAR
}

\author{
Luis Eugênio Martiny \\ Instituto Federal de Educação, Ciência e Tecnologia, do Rio Grande do Norte, Na- \\ tal, Rio Grande do Norte, Brasil.
}

\section{Pierre Normando Gomes-da-Silva}

Universidade Federal da Paraíba , João Pessoa, Paraíba, , Brasil

\begin{abstract}
Resumo
O objetivo do presente trabalho foi (re)conhecer a observação como elemento da prática pedagógica dos professores em formação inicial. A pesquisa teve duração de três meses e foi realizada em uma escola pública de João Pessoa (PB). Participaram da investigação três acadêmicos do curso de Educação Física da UFPB. As técnicas de coleta foram: observação participante, grupo focal e documentos escritos. Foram analisadas oito aulas de cada acadêmico. Utilizou-se a técnica de análise de conteúdo. Foram identificados três tipos de observação: a) espelhada; b) incorporativa; c) corporativa. Estes tipos se converteram em três estágios: a) sincrético; b) analítico; c) correlato. Aponta-se que a observação não somente corrobora no processo de transposição didática, mas constrói também um saber coletivizado.
\end{abstract}

Palavras chave: Observação. Transposição. Aprendizagem.

\section{Introdução}

A complexidade da docência na área da Educação Física (EF) tem gerado significativas discussões, principalmente acerca da configuração da formação superior. Um destes enfrentamentos tem acontecido na perspectiva de estabelecer quais saberes, dentro de um universo expressivo de conhecimentos, habilidades e competências, necessitam ser abordados nos diferentes contextos de formação dos professores.

A manifestação desta pluralidade de saberes que são atribuídos aos docentes leva-nos também a refletir sobre a relação existente entre a formação inicial e o campo de atuação. Todo este cenário exposto abre a possibilidade de se problematizar como ocorre esta transferibilidade de saberes da formação inicial para o campo de intervenção.

Pensar a Prática, Goiânia, v. 17, n. 3, p. 766-782, jul./set. 2014 
A relação que aqui é estabelecida faz com que se torne relevante investigar a disposição destes saberes docentes (SD) no contexto da formação inicial e a sua manifestação na prática educativa dos professores em sala de aula. Uma prática pedagógica que, segundo Perrenoud (1993), está sempre permeada por três faces: a) a face da rotina e improvisação regulada; b) a face do tratamento das diferenças e c) a face da transposição didática (TD).

O aprofundamento das análises acerca desta terceira faceta, ou seja, desta possível transferibilidade de saberes, acaba por recair diretamente sobre a ação pedagógica do professor. $\mathrm{Na}$ análise desta ação pode-se, então, identificar dois grupos de saberes docentes: a) os saberes para ensinar, aqueles saberes que os auxiliam na realização do seu oficio docente, e b) os saberes a serem ensinados, aqueles saberes que se tornam objetos de ensino e ocupam um lugar no currículo (formal ou oculto) da escola (adaptados de TARDIF, 2008).

Portanto, quando falamos da avaliação desta possível transferibilidade destes dois grupos em relação aos dois contextos - formação/intervenção - isto pode, segundo Hernández (2004), garantir mudanças nas práticas educativas (pedagógicas) dos docentes.

O reconhecimento de que existe um processo que se faz necessário para modificar os saberes, sejam eles a ensinar e/ou para ensinar não é algo distante do meio educacional/formativo. Ao contrário, este processo de transformar o saber e discutir a sua trajetória tem sido alvo de significativas investigações entre os pesquisadores dentro do campo educativo (BERNSTEIN, 2003; GIMENO-SACRISTAN; PÉREZ GÓMEZ, 2000; PERRENOUD, 1993; 2002).

Para Chevallard (1998, p. 39), por exemplo, a TD passa a ser este trabalho que faz de um objeto de saber a ensinar, objeto de ensino. É este conjunto destas transformações adaptativas que irão torná-lo apto a ocupar um lugar entre os saberes curriculares.

Silvestre (2011), em seus estudos sobre as práticas de ensino e os estágios supervisionados, sinaliza que as vivências de formação possuem a ideia de que o domínio dos conteúdos específicos (saberes a ensinar) passa a ser a primeira condição para exercer o magistério, e que o fazer, a ação de ensinar, se aprende pela própria prática, principalmente por meio da observação e do modelo a seguir.

Sendo assim, nos deparamos com a seguinte pergunta problematizadora: em que medida os Professores em Formação Inicial (PFI) conseguem redimensionar os saberes adquiridos na formação inicial e aplicá-los no contexto escolar?

Para conseguir realizar aproximação a esta questão norteadora, buscamos (re) conhecer e avaliar um dos elementos - observação - que sustenta 
a prática pedagógica destes PFI e os auxilia neste processo da TD. O aprofundamento das análises deste elemento na prática pedagógica dos PFI pode abrir possibilidades de reconhecer as suas implicações com a transferibilidade dos saberes docentes da formação para a intervenção.

\section{Metodologia}

A interatividade com o objeto de estudo apontou para alguns princípios que conduziram esta investigação para uma pesquisa de abordagem qualitativa (MINAYO, 1999), do tipo ação (THIOLLENT, 2004), por meio de uma metodologia colaborativa (BEZERRA TINOCO, 2007; GOMESDA-SILVA, 2009).

\section{Os professores em formação inicial (PFI) - colaboradores da pesquisa}

Os colaboradores da pesquisa se identificaram como sendo os PFI do curso de graduação em EF - Licenciatura Plena da Universidade Federal da Paraíba (UFPB). Para efeito de participação na investigação desenvolvemos a pesquisa com os PFI que: a) estavam matriculados no componente curricular Prática de Ensino em Educação Física no semestre 01/2011; b) que realizaram a sua intervenção prática em escola pública municipal da cidade de João Pessoa - PB e que c) desenvolveram esta intervenção no Ensino Fundamental I.

Entretanto, não adotamos como colaboradores da pesquisa os PFI que: a) já haviam atuado em escola como professores antes da realização do estágio supervisionado; b) já tinham adquirido mais de um ano de experiência docente como professores de escola; c) dispunham de outro curso de Magistério e/ou Licenciatura e, por fim, d) realizaram a sua intervenção prática em escola de caráter privado.

Tivemos três PFI, dois do sexo feminino e um do sexo masculino, como sendo os colaboradores da pesquisa. Acompanhamos as aulas no ambiente escolar e coletamos informações destes três PFI, que aqui passam a ser representados pelos nomes fictícios de Luiza, Madalena e João. Luiza ministrando aulas no $1^{\circ}$ ano, Madalena realizando o seu estágio com a turma do $2^{\circ}$ ano e João fazendo as suas aulas com a turma do $3^{\circ}$ ano, todos do Ensino Fundamental I.

\section{Técnicas para coleta de dados}

As técnicas que utilizamos para a coleta de dados foram correlacionadas aos procedimentos apontados na metodologia colaborativa (BEZER- 
RA TINOCO, 2007; GOMES-DA-SILVA, 2009). Foram utilizadas três diferentes técnicas mediadoras de coleta de dados: a) Observação Participante (OP), com descrição de comportamento em diário de campo; b) Realização de Grupos Focais (GF), com perguntas abertas, que se converteram em temas geradores e; c) Documentos Escritos (DE), pelos PFI, mais especificamente o memorial descritivo (MD), a narrativa de formação (NF) e as sessões reflexivas (SR).

\section{Procedimentos metodológicos para coleta de dados}

A pesquisa teve a duração de aproximadamente três meses e foi realizada em uma escola pública da cidade de João Pessoa - PB no primeiro semestre do ano de 2011. Este tempo de execução da pesquisa foi interrelacionado às exigências mínimas da carga horária do componente curricular Prática de Ensino em Educação Física. O componente acontece no sexto período do curso de Graduação em Educação Física da UFPB e tem uma carga horária de $150 \mathrm{~h}$.

O processo metodológico de coleta de dados foi estruturado em duas dimensões. Estas dimensões definiram-se como sendo macro e microestruturantes e percorreram toda a ação investigativa. A dimensão macroestrutural foi composta de sete fases e teve um caráter longitudinal, conforme apresentamos no Quadro 1 a seguir.

\section{Quadro 1 - Descrição longitudinal do processo metodológico}

\begin{tabular}{|c|c|c|}
\hline Fases & Temáticas & Descrição \\
\hline 1 & $\begin{array}{l}\text { Seminários } \\
\text { temáticos }\end{array}$ & $\begin{array}{l}\text { Elaboração e estruturação dos planos de ensino } \\
\text { Procedimentos didáticos (ONOFRE, 1995) } \\
\text { Orientações para elaboração das sessões reflexi- } \\
\text { vas (MAGALHÃES, apud TINOCO, 2007) }\end{array}$ \\
\hline 2 & $\begin{array}{l}\text { Reconhecimento do } \\
\text { campo do estágio }\end{array}$ & Ambiente educacional \\
\hline 3 & Sessão reflexiva $(01)$ & Descrição do que viram e vivenciaram na escola \\
\hline 4 & Aulas laboratórios & $\begin{array}{l}\text { Ministrar aulas dentro da proposta pedagógica } \\
\text { adotada }\end{array}$ \\
\hline 5 & Sessão reflexiva (02) & Descrição sobre as aulas ministradas \\
\hline 6 & Aulas laboratórios & $\begin{array}{l}\text { Ministrar aulas dentro da proposta pedagógica } \\
\text { adotada }\end{array}$ \\
\hline 7 & Sessão reflexiva (03) & $\begin{array}{l}\text { Descrição de uma ação transformadora do está- } \\
\text { gio e uma autoavaliação formativa }\end{array}$ \\
\hline
\end{tabular}

Pensar a Prática, Goiânia, v. 17, n. 3, p. 766-782, jul./set. 2014 
Já a segunda dimensão com característica mais microestrutural adquiriu qualidades mais transversais. Isto porque acontecia dentro de cada dia de intervenção no estágio. Estas aulas foram realizadas sistematicamente nas segundas, quartas e sextas-feiras. Cada aula ministrada seguiu o tempo de 40 minutos de duração, conforme os períodos da escola. As aulas que foram observadas e registradas, na soma dos três PFI, perfizeram um total de 24 aulas para efeitos de coleta e posterior análise de dados.

A cada dia de intervenção no estágio, os três professores ministravam cada um deles uma aula. Estas aulas aconteciam em períodos distintos um do outro. O tempo dos PFI no ambiente do estágio em cada dia iniciava às $13 \mathrm{~h}$ e terminava às $17 \mathrm{~h}$. No transcorrer destas $4 \mathrm{~h}$, eles ministravam uma aula cada um e observavam as aulas dos outros três colegas.

Logo após o término do conjunto de aulas aconteciam os grupos focais (GF). Eles acompanharam o andamento dos dias das aulas no estágio, portanto perfazendo oito encontros, e tiveram uma duração de tempo em média de 35 minutos.

A coleta de dados foi realizada em três etapas: a) antes do início das aulas do estágio, com a coleta do memorial descritivo e da narrativa de formação, b) durante a realização das aulas do estágio, com a coleta das sessões reflexivas 1 e 2, das observações participantes com registros dos comportamentos em diário de campo, e da realização dos grupos focais com a gravação de áudio e c) após o término das aulas do estágio com a coleta da sessão reflexiva 3 .

Todo este material construído foi coletado junto a Luiza, Madalena e João durante todo o processo metodológico. Para fins de tratamento e análise das informações coletadas, todas as falas realizadas, tanto nas aulas como no GF foram transcritas. Após a transcrição, estas falas foram devolvidas a Luiza, Madalena e João para autorizarem a sua publicação. Cabe ressaltar também que o projeto foi aprovado junto ao Comitê de Ética da UFPB pelo protocolo $\mathrm{n}^{\circ}$ 032/2011.

\section{Tratamento e análise dos dados}

Para análise e tratamento dos dados coletados foi adotada a proposta de análise de conteúdo de Bardin (2008). Para que as apreciações pudessem acontecer foi utilizada a técnica de análise de conteúdo do tipo categorial por temática. A partir de então, foram catalogadas as informações coletadas por meio dos textos escritos, falas, e observações registradas em diário de campo em categorias temáticas. Para conseguir avaliar as Falas, os textos escritos e as Observações (FEO), a análise foi realizada a partir da teoria dos 
SD e formação profissional de Tardif (2008), em interlocução com a teoria da TD de Chevallard (1998).

\section{Resultados}

De acordo com as análises iniciais realizadas e com as delimitações do estudo, a primeira unidade de contexto (UC) identificada, sobre as FEO dos PFI, dentro da CT componente curricular, foi a prática pedagógica. Uma unidade detectada que se caracterizou arrolada ao processo metodológico colaborativo do estágio supervisionado e incidiu sobre a atuação destes professores.

A proximidade desta atuação com a metodologia colaborativa nos possibilitou ainda a identificação de três unidades de registro (UR) que se converteram nos elementos que sustentam a prática pedagógica dos PFI. Um destes elementos é o da observação ${ }^{1}$ que evidencia as percepções percebidas.

A partir de então, identificamos e (re)conhecemos uma significativa relevância, deste elemento observação e sua influencia a atuação dos PFI quando em sala de aula. Este elemento, juntamente com os elementos da discussão nos grupos focais e da reflexão parecem se transformar em pontos de apoio para a formação do professor, até mesmo das suas identidades como docentes. Podemos visualizar estas impressões nas falas e escritas de Luiza e Madalena, que apresentamos a seguir:

Enfim, as minhas atitudes e metodologia melhoraram graças aos grupos focais. As minhas aulas foram muito proveitosas e divertidas tanto pra mim quanto para os meus alunos. [...] Saio da escola [...] me sentindo uma professora de verdade, pronta para os desafios que me serão designados, (LUIZA - $3^{\mathrm{a}}$ sessão reflexiva).

Não foram poucas as noites que passei em claro tentando elaborar uma melhor aula para meus alunos, mas mesmo me empenhando, muitas vezes as aulas não se saiam como eu planejava e isso a principio me deixou frustrada, contudo nos grupos focais e mesmo entre uma aula e outra um colega ou outra conversava e [...] o nosso supervi-

1Os outros dois elementos seriam: o elemento da reflexão, que se manifesta nas ações dos PFI e o elemento das discussões do grupo focal que assume o centro das discussões e se caracteriza como um tempo-espaço de discussão através das observações feitas e das reflexões realizadas;

Pensar a Prática, Goiânia, v. 17, n. 3, p. 766-782, jul./set. 2014 
sor sempre nos consolava dizendo que isto fazia parte das aulas, (MADALENA - $3^{\mathrm{a}}$ sessão reflexiva).

As falas evidenciam que os elementos serviam de suporte para a reflexão e a construção formativa dos PFI. Já no campo específico das observações, pudemos encontrar três tipos de olhares que os docentes fazem quando se colocavam como expectadores/avaliadores dos seus colegas. Um primeiro olhar se definiu como uma observação espelhada, ou seja, o PFI ao ver a aula do seu colega, realiza reflexões sobre as suas próprias ações e as compara mentalmente com as dele. Expressões do tipo "eu faço isso"; "eu não faço assim", "será que eu faço deste jeito?" se tornam presentes neste tipo de observação (falas observadas e registradas no diário de campo). Podemos evidenciar isto a exemplo da fala de Luiza, que apresentamos a seguir:

As observações têm sido muito proveitosas, pois consigo me ver aplicando a aula além de me corrigir através destas para poder melhorar na próxima. Não vejo as observações como um ponto negativo, aliás, aprendo muito com elas me faz ver onde estou errando, o que tenho que melhorar, o que posso mudar, enfim, está sendo um grande crescimento profissional pra mim e posso dizer também pessoal. A gente acaba aprendendo que uma crítica nem sempre é destrutiva, e neste caso então, nem se fala. (LUIZA $-1^{\text {a }}$ Sessão reflexiva)

O segundo olhar faz referência a uma observação incorporativa, visto que, quando o PFI observa o seu colega ministrando a aula, ele se apropria das ações/ estratégias/tarefas que fez e as traz para a sua aula. Este segundo olhar pode ser percebido, a exemplo da escrita de Madalena.

Foi muito difícil me encontrar como professora, eu não me enxergava gritando ou tocando nas crianças para discipliná-las, na realidade a agressividade dos alunos me assustou bastante e eu demorei um pouco para perceber que eu teria que me impor e para que isso ocorresse eu deveria tomar uma atitude, a decisão foi imposta pelos meus amigos colaboradores sempre que acabava a aula dizia que eu precisava controlar e gritar com os alunos para que os mesmos me obedecessem. Se não fossem tantas criticas eu jamais teria conseguido. (MADALENA sessão reflexiva - autoavaliação)

Pensar a Prática, Goiânia, v. 17, n. 3, p. 766-782, jul./set. 2014 
Por fim, ainda há uma observação corporativa, quando o PFI olha a aula do colega e tece comentários sobre ela na expectativa de ajudá-lo na sua intervenção docente. Na grande maioria das vezes isto acontece no grupo focal, para apoiar, motivar e/ou melhorar a aula do colega e por vezes até a sua forma de atuação. Esta observação pode ser vista na escrita de João, por exemplo, que apresentamos a seguir.

\begin{abstract}
De acordo com as observações feitas pelos meus colegas, uma das minhas principais dificuldades no início era manter a concentração dos alunos na aula e durante a minha explicação, pois eles ficavam muito dispersos. Realmente sentia necessidade de aprimorar algo em mim para melhorar esse meu lado de chamar a atenção. Então comecei a observar algumas aulas dos meus colegas e passei a adotar alguns métodos presentes nas aulas deles. Quando os alunos começavam a se dispersar ou conversar demais eu batia palmas e se caso não adiantasse eu aumentava a minha voz pedindo silêncio. Então percebi que estava dando efeito e os alunos passavam a ter mais receio de quando eu utilizava dessas medidas e aula voltava a fluir normalmente. (JOÃO - $2^{\mathrm{a}}$ sessão reflexiva)
\end{abstract}

\title{
Discussão
}

No conjunto dos elementos que reconhecemos auxiliar a prática pedagógica dos PFI conjuntamente com o seu ser professor, encontramos a observação. Este elemento que acabou se manifestando em três tipos de olhares (espelhado, incorporativo e corporativo) de certa forma tem a sua centralidade mais pontualmente, quando os PFI se colocavam como expectadores/avaliadores dos seus colegas quando estes ministravam suas aulas.

Antes ainda, é importante reconhecer que a observação não somente era feita nestes momentos. Os PFI não deixavam de observar quando estavam em um momento de formação, num seminário temático, nem tampouco quando ministravam a sua própria aula. Aliás, esta última gera outro tipo de observação, ou seja, a observação do comportamento/ atitudes e falas dos seus alunos. Algo que consideramos ser fundamental à ação docente na relação com a aprendizagem dos educandos. Todavia, pelos limites dados a esta investigação, estes dois novos contextos de observação não foram contemplados neste momento de análise e discussão.

Ao situar o contexto da observação no plano de expectadores, isto já nos direciona para alguns pontos de apreciação. Pontos estes que emergem

Pensar a Prática, Goiânia, v. 17, n. 3, p. 766-782, jul./set. 2014 
da situação dos PFI observarem os seus colegas, fato que os coloca na condição de análise das suas práticas. Uma análise de dupla direção, conforme podemos perceber nos resultados. Ao mesmo tempo em que analisava a prática pedagógica do seu colega de grupo acabava fazendo uma autoanálise representativa da sua.

Em um primeiro momento, esta análise, de imediato já transforma a idéia de que os PFI se sintam sós e desassistidos no estágio. Há presente um colaborador que irá ajuda-lo na sua prática. Nos estudos de Moletta et al. (2013), por exemplo, a ausência de supervisores (avaliadores colaboradores) foi um dos piores momentos que marcaram o estágio dos acadêmicos.

Em segundo momento, a observação para os PFI passa a ser um procedimento para coletar dados que indicam o que está acontecendo no ambiente observado. As informações captadas leva o PFI a fazer uma espécie de mapeamento do que está ocorrendo. A partir deste mapeamento, os resultados nos permitiram também evidenciar que o PFI acaba traçando alguns propósitos para sua ação futura. Este cenário criado a partir da observação coletora de dados, mapeadora de contextos e possível reguladora da ação dos PFI nos possibilita três tópicos de análise.

O primeiro deles fica direcionado à criação de um jeito de olhar. Esta criação está relacionada a um olhar designado. Parte-se sempre do questionamento sobre o que observar. Num primeiro momento os PFI tendem a observar tudo. No início tudo pode interessar, tudo pode chamar a atenção. É como se estivessem em um estado de apreciação e catalogação.

Esta fase inicial da observação pode gerar, aparentemente, uma confusão no olhar e no que se percebe com o olhar. A limitação se acentua quando se busca correlacionar o que foi observado com possíveis aproveitamentos para a ação docente. Esta visão turva da realidade pode confundir as decisões que precisam ser tomadas.

O que o PFI observa passa a manifestar uma forma de leitura do real. Ele elabora representações sobre o contexto vivido, do que ele percebe da situação concreta vivenciada. Esta forma como percebe o contexto pode influenciar diretamente na maneira como atua. Isto visto que estes ambientes observados estão cheios de informações que necessitam ser captadas, selecionadas e interpretadas. É a partir da maneira como faz a decodificação destas informações que seus projetos de atuação como docente podem ser desencadeados.

Sinaliza-se, neste sentido, um primeiro estágio de observação dos PFI. Aparentemente, eles passam neste momento inicial da intervenção por realizar uma observação sincrética. Eles procuram conseguir fazer a junção, ainda que de forma elementar, de um conjunto de elementos que estão presentes no ambiente observado e que serão úteis para a sua ação docente.

Pensar a Prática, Goiânia, v. 17, n. 3, p. 766-782, jul./set. 2014 
Buscam fazer sínteses dos diferentes contextos observados, das diferentes ações dos seus colegas e das suas próprias aulas. Esta condição de realizar composições exige dos PFI a criação deste jeito de olhar a realidade.

Com o desenrolar das aulas, com o exercício constante da observação, os PFI sinalizam que vão clareando este olhar. Ao longo do processo do estágio, eles vão amadurecendo e ajustando a observação. Vão criando assim uma forma de ver a realidade observada. Personificam um jeito de assistir o que está acontecendo na prática pedagógica do seu colega de grupo e, por conseguinte, de fazer retroavaliações comparativas com a sua aula.

Isto fica evidente na escrita de Luiza, quando esta manifesta a sua observação espelhada. A PFI relata que foi ajustando este olhar ao longo das aulas e que foi observando o que tinha que melhorar e mudar neste desenrolar das observações ( $1^{\text {a }}$ sessão reflexiva). Esta situação nos aproxima dos estudos de Melo (2008), quando relata a sua experiência com o estágio curricular e a formação de professor de um curso de Pedagogia. A autora fala da necessidade de um aguçamento do olhar do PFI. Isto visto que, para ela, o cotidiano escolar é um espaço de múltiplas relações, o que acaba requerendo do PFI um olhar atento para poder captar o máximo de detalhes que estão presentes na intrincada teia de relações que se estabelecem dentro deste contexto.

A fala de Luiza denota que os PFI amadureceram seu olhar ao longo do estágio. A partir deste amadurecimento no olhar, percebe-se que os PFI foram além neste processo de observação. Quando os três PFI relatam que começaram a incorporar ações observadas nas aulas uns dos outros e que se arriscavam, inclusive em fazer apontamentos sobre a aula do colega. As observações ganharam uma elaboração representativa da sua própria intervenção.

Isto é o que confirma, até mesmo, o amadurecimento atingido pelo PFI no desenrolar do estágio. Maturidade manifestada pelo reconhecimento, na ação do colega professor ou no comportamento dos alunos, de estratégias de ensino, de acertos ou erros metodológicos, semelhanças e distanciamentos com a abordagem pedagógica adotada por eles.

Esta criação de diferentes olhares também nos permite sinalizar que o ideal de docente, do ser professor, vai se construindo e solidificando neste processo de observação dos seus pares e na comparação com a sua atuação pedagógica. O que dá a esta observação uma função de compreensão do que está acontecendo com o PFI na vivência prática, nas transformações que sofre como docente. Isto pode entrar em oposição ao que normalmente acontece no cotidiano escolar, quando o docente não consegue reconhecer estas mudanças.

Pensar a Prática, Goiânia, v. 17, n. 3, p. 766-782, jul./set. 2014 
Tudo isto evidencia o surgimento de um filtro regulador das informações que são observadas. Há um aprofundamento perceptivo. Se no início tudo importava, tudo era relevante, ao final do estágio a observação já segue um direcionamento, já há um foco do que deverá ser observado. Por exemplo, o PFI em observação quer ver como o colega que está ministrando aula faz para resolver os conflitos que surgem a partir das dificuldades vividas, como faz para lidar com a transferibilidade do saber, como trata o objeto a ser ensinado. Este olhar já é uma observação intencionada. O PFI já a faz buscando na aula do colega semelhanças com as situações-problema que enfrentou na sua sala de aula. Há, portanto, a busca por sinais relevantes que o permitam melhorar o seu saber ser e fazer pedagógico, melhorando inclusive a forma de trabalhar com estes saberes e transferi-los para o contexto da aula.

Esta descrição evidencia um segundo estágio de observação dos PFI. Sinaliza-se, desta forma, uma observação analítica. A observação, neste estágio, passa a ser sistematizada e direcionada. Eles sabem o que precisa ser observado, como irão fazer para observar e quando deverão fazê-lo. Neste estágio, as observações dos PFI oferecem sinais de se aproximarem aos quatro sub-processos apontados por Abernethy et. al., (2001), que condicionam esta capacidade de observação numa perspectiva analítica.

Os PFI passaram por um processo de detecção, que determina se os sinais relevantes estão presentes ou não no contexto observado. Logo após, estabeleceram um processo de comparação, ou seja, apontaram se os sinais detectados são iguais ou diferentes aos que já foram percebidos em outras situações. Após, fizeram um reconhecimento destes sinais, identificando-os como previamente experimentados e, por fim, constituíram uma atenção seletiva, que filtra fatos de interesse, não mais se importando com os menos relevantes, ou os que já não são tão pertinentes para a prática pedagógica.

Tudo isto desencadeia uma necessidade que Weffort (1997) chama de "aprendizagem do olhar". Numa primeira dimensão o PFI aprende observando os colegas. Um aprender que é ressignificador, pois ele reavalia não somente o outro, mas a si próprio, podendo inclusive mudar ou permanecer nos seus comportamentos, nas suas atitudes e nas suas bases de conhecimento teórico-prático. Já em uma segunda dimensão ele aprende a observar, pois, além de criar este jeito de olhar que personifica, realizando uma observação sincrética, ele intenciona este olhar, elabora filtros reguladores da observação para, enfim, detectar sinais relevantes mais aproximativos ao seu contexto de ação. O que caracteriza a aprendizagem do olhar para uma observação analítica, portanto sistematizada.

Desta dupla direcionalidade surge o próximo ponto de discussão. A observação, seja ela espelhada, incorporativa ou corporativa nos PFI, passa

Pensar a Prática, Goiânia, v. 17, n. 3, p. 766-782, jul./set. 2014 
também a ser um elemento que desencadeia a reflexão. Ainda que este caminho seja multilateral, visto que a reflexão pode também desencadear a necessidade da observação. Isto acontece, por exemplo, quando João, ao observar a aula de Luiza, relata que percebeu a forma como a colega chamava a atenção dos alunos, refletiu se isto poderia ser utilizado na sua aula e após a reflexão começou a adotar tal estratégia na sua prática. Entretanto, a reciprocidade acontece quando João, no caminho inverso, já havia refletido e identificado este problema como um delimitador da sua ação pedagógica antes mesmo da aula de Luiza. Contudo, ele foi buscar por meio da observação da aula da colega respostas para a sua dificuldade $\left(2^{\mathrm{a}}\right.$ sessão reflexiva).

Esta relação feita com a reflexão faz surgir um terceiro estágio de observação. O PFI realiza uma observação correlata. É a partir dela e por meio dela que o PFI faz reflexões acerca da sua ação docente, do contexto escolar, da prática pedagógica dos colegas, dos saberes envolvidos e da aprendizagem dos alunos sobre os conteúdos, ou objetos de ensino.

Pela observação correlacionada ao elemento reflexão, o PFI pode refletir e perceber, por exemplo, que não há comportamentos iguais para problemas diferentes. $\mathrm{O}$ agir não pode ser igual quando há situações distintas. Num sentido mais aberto, ele, a partir da observação que gera a reflexão, termina por tomar consciência da provisoriedade da prática e da complexidade da ação docente, ou conforme apontado por Rezer e Fenstenseifer (2008), da necessidade de resgatá-la. A observação, neste sentido, pode reorientar as ações pedagógicas feitas pelo PFI, fato este até mesmo confirmado pelos resultados.

Além disso, pela observação o PFI pode se reconhecer na tensão do que ele deseja ser e do que ele realmente faz. A observação, neste caso, levou os PFI a buscar certa coerência prática na concepção da aula e na metodologia adotada. Isto entra em oposição aos achados de Michellotti e Souza (2008), quando desvelaram que os professores não possuíam clareza nos conhecimentos teórico-metodológicos utilizados nas suas próprias ações pedagógicas.

Neste sentido, os PFI, ao observarem, conseguem estabelecer duas rotas de comunicação. Uma primeira com a reflexão, pois acabam revendo as suas práticas pedagógicas. Eles acabam, conforme apontamos anteriormente, refletindo sobre elas, a partir das observações e reflexões feitas. Isto acontece pelo fato da observação, ao mesmo tempo, permitir ao PFI a olhar para si mesmo, para resolver os seus problemas, como também olhar para o outro, para ajudá-lo a melhor compreender os problemas dele.

Já uma segunda rota acontece com os seus saberes docentes. Saberes estes que estão na sua base de conhecimento (BORGES, 2004). Neste senti-

Pensar a Prática, Goiânia, v. 17, n. 3, p. 766-782, jul./set. 2014 
do, a observação além de já vir repleta de saberes, que são provenientes das mais variadas fontes sociais de aquisição (TARDIF, 2008), termina também por ser uma fonte de ampliação desta base de conhecimento do docente.

O quadro 2, a seguir, apresenta o elemento observação com seus tipos problematizados. Esta problematização abriu diálogos com as suas funções operativas, com os seus processos e os seus diferentes estágios.

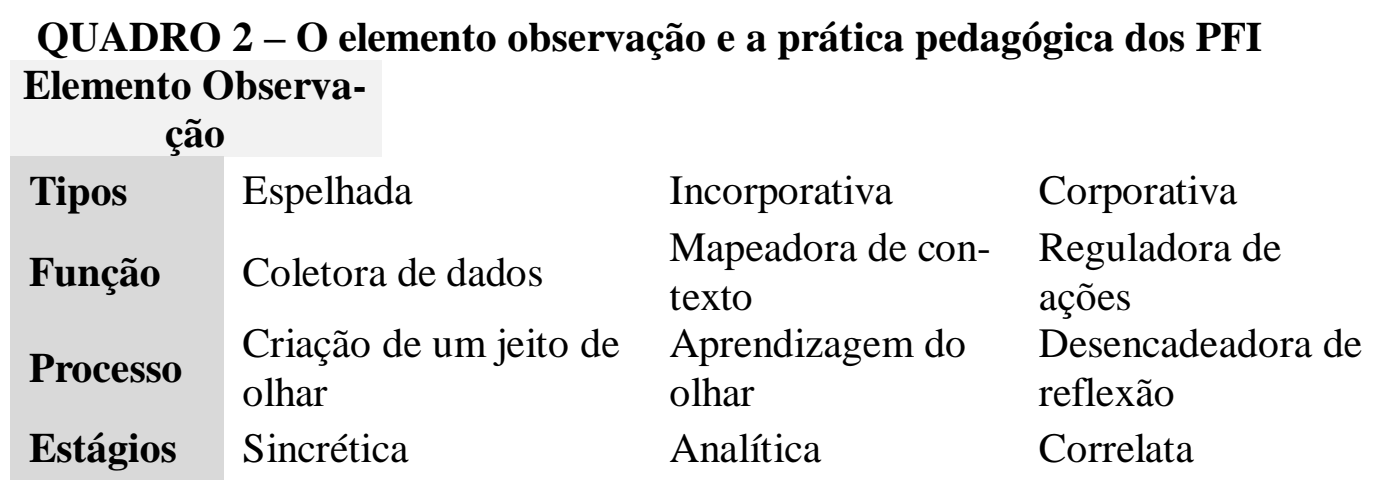

\section{Conclusão}

A criação deste jeito de olhar, com suas intencionalidades, ajustamentos, filtros reguladores e sinais relevantes, somados aos desdobramentos comunicativos com a reflexão e os saberes docentes, marca a observação feita pelos PFI a partir de três estágios (sincrético, analítico e correlato). Estes três estágios permitiu a eles o desenvolvimento de um olhar crítico-reflexivo acerca da prática pedagógica, seja a sua própria ou a do colega, da cultura escolar, da aprendizagem dos conteúdos por parte dos alunos e que se reflete, portanto, na transposição dos saberes.

Além disso, este olhar crítico aproxima os PFI à formação de um professor pesquisador. Neste sentido, as observações feitas no e durante o estágio pelos PFI corroboram na formação do professor reflexivo e investigador.

Isto fica mais evidente quando identificamos não somente os seus tipos, mas também as suas funções, quando ela passou a ser coletora de dados, mapeadora de contextos e possível reguladora da ação dos PFI. Para isto os PFI a utilizam como espelhada, incorporativa e corporativa sendo desenvolvida/utilizada nos estágios Sincrético, analítico e correlato.

A relação com a TD, mais especificamente, acontece quando o PFI toma como referencia as estratégias de ação, as formas de apresentação do objeto de ensino, a transferibilidade do contexto da formação para a intervenção e desta intervenção para os seus colegas e entre eles mesmos. Há a 
indicação de um desdobramento da TD e dos SD, ocasionado pela aprendizagem do olhar, por observar o seu colega ministrando aulas.

A observação possibilita a construção e formação de um trabalho docente pedagógico alicerçado na coletividade. Está condição nos aponta para um possível saber coletivizado, construído e forjado na troca existencial entre os PFI, ou seja, no momento de uma observação espelhada, incorporativa e corporativa.

\title{
THE OBSERVATION REFLECTIVE PEDAGOGICAL PRACTICE OF TEACHERS IN INITIAL CONSTITUENT OF DIDACTIC TRANSPOSI- TION OF KNOWLEDGE TO TEACH
}

\begin{abstract}
The objective was to (re) learn the observation as part of the pedagogical practice of teachers in initial training. The study lasted three months and was held in public school João Pessoa (PB). Participated in the investigation three students of Physical Education UFPB. The techniques were: participant observation, focus group and written documents; were analyzed 8 classes each academic. We used the technique of content analysis. Recognized three types of observation: a) Mirror b) incorporative c) corporate. These types were converted into three stages: a) syncretic b) analytical c) correlate. It is pointed out that the observation not only supports the process of didactic transposition, but also builds a knowledge collectivized.

Keywords: Observation. Transposition. Learning.

\section{LA OBSERVACIÓN DE LA PRÁCTICA PEDAGÓGICA REFLEXIVA DE LOS DOCENTES EN CONSTITUYENTE INICIAL DE TRANSPOSICIÓN DIDÁCTICA DE LOS CONOCIMIENTOS PARA ENSEÑAR}

\section{Resumen}

El objetivo fue ( re) aprender de la observación como parte de la práctica pedagógica de los docentes en la formación inicial. El estudio duró tres meses y se llevó a cabo en la escuela pública João Pessoa (PB). Participaron en la investigación tres estudiantes de UFPB Educación Física. Las técnicas fueron: observación participante, grupos focales y documentos escritos; se analizaron 8 clases cada académico. Se utilizó la técnica de análisis de contenido. Reconocido tres tipos de observación: a)Espejo b) incorporative c) corporativo . Estos tipos se convirtieron en tres etapas: a) sincrética b) analítica c) se correlacionan. Se señala que la observación no sólo es compatible con el proceso de transposición didáctica, pero también construye un conocimiento colectivizado .

Palabras-claves: Observación. Adaptación. Aprendizaje.

Pensar a Prática, Goiânia, v. 17, n. 3, p. 766-782, jul./set. 2014 


\section{Referências}

ABERNETHY, B; WANN, J; PARKS, S. Treinamento das habilidades perceptivo-motoras no esporte. In: ELLIOT, B; MESTER, J. (org.). Treinamento no Esporte: aplicando ciência no esporte. Guarulhos: Forte Editora, 2001.

BARDIN, L. Análise de Conteúdo. 8 ed. Lisboa: Edição 70, 2008.

BERNSTEIN, B. A pedagogização do conhecimento: estudos sobre recontextualização. Cadernos de Pesquisa, n. 120, novembro, 2003.

BEZERRA-TINOCO, E. J. Educar para a solidariedade: uma perspectiva para a educação física escolar. 345 fl. Tese (doutorado) Programa de Pósgraduação em Educação. Universidade Federal do Rio Grande do Norte. Natal RN, 2007.

BORGES, C. 2004. O professor de Educação Básica e seus saberes docentes. Araraquara: JM, 2004.

CHEVALLARD, Y. La transposición didáctica: del saber sabio al saber enseñado. 3 ed. Buenos Aires: AIQUE, 1998.

GIMENO-SACRISTÁN, J.; PÉREZ GÓMEZ, A. I. Compreender e transformar o ensino. Porto Alegre: Artmed, 2000.

GOMES-DA-SILVA, P. N. Prática de ensino em educação física: por uma formação do professor-pesquisador. In: HERMIDA, J.F (Org.). Educação Física: Conhecimento e saber escolar. João Pessoa: Editora universitária UFPB, p.103-128, 2009.

HERNANDEZ, F. A formação do professorado e a investigação sobre a aprendizagem dos docentes. In: MOLINA NETO, V.; TRIVIÑOS, A. N. (Org.). A pesquisa qualitativa na Educação Física: Alternativas Metodológicas. 2 ed. Porto Alegre: UFRGS, p. 45-60, 2004.

MELO, G. F. Estágio na formação inicial de professores: aguçando o olhar, desenvolvendo a escuta sensível. In: SILVA, L. C.; MIRANDA, M. I. (Org.). Estágio Supervisionado e prática de ensino: desafios e possibilidades. Araraquara, SP: Junqueira\&Marin, p. 85-114, 2008. 
MICHELOTTI, D. V; SOUZA, M. S. Análise do Conhecimento TeóricoMetodológico dos Professores em Educação Física do CEFD/ UFSM em Relação à sua Prática Pedagógica. Movimento, Porto Alegre, v. 14, n. 2, p. 63-82, maio/agosto 2008.

MINAYO, M. C. S. O desafio do conhecimento: Pesquisa qualitativa em Saúde. 6 ed. São Paulo- Rio de Janeiro: Hucitec - Abrasco, 1999.

MOLLETA, A.F et. al. Momentos marcantes do estágio curricular Supervisionado na formação de Professores de educação física. Pensar a Prática: Goiânia, v.16, n.3, p.619955, jul./set. 2013.

ONOFRE, M. S. Prioridades de formação didática em Educação Física. Boletim da Sociedade Portuguesa de Educação Física, n. 12, p. 75-97, inverno/primavera, 1995.

PERRENOUD, P. A prática reflexiva no ofício de professor: Profissionalizçaão e razão pedagógica. Porto Alegre: Artmed, 2002.

PERRENOUD, P. Práticas Pedagógicas, profissão docente e formação. Perspectivas sociológicas. Lisboa: D. Quixote, 1993.

REZER, R. FENSTERSEIFER, P. E. Docência em Educação Física: Reflexões acerca de sua complexidade. Pensar a prática, v. 11, n 3. 2008.

SILVESTRE, M. A. Prática de Ensino e Estágios Supervisionados: da observação de modelos à aprendizagem da docência. Rev. Diálogo Educ. Curitiba: v. 11, n. 34, p. 835-861, set./dez. 2011.

TARDIF, M. Saberes docentes e formação profissional. 9 ed. Petrópolis: Vozes, 2008.

THIOLLENT, M. Metodologia da Pesquisa-ação. 13 ed. São Paulo: Cortez, 2004.

WEFORD, M. F. Educando o olhar da observação. In: WEFORD, M. F. WEFFORT, M. F. Observação, registro, reflexão, instrumentos metodológicos I, Espaço Pedagógico, 2 ed. p. 1-20, 1007. 
Recebido em: 08/10/2013

Revisado em: 28/11/2013

Aprovado em: 03/02/2014

Endereço para correspondência:

luis_martiny@hotmail.com

Luis Eugênio Martiny

Instituto Federal de Educação, Ciência e Tecnologia do Rio Grande do Norte | Reitoria

Rua Dr. Nilo Bezerra Ramalho, 1692, Tirol

CEP: 59015-300

Pensar a Prática, Goiânia, v. 17, n. 3, p. 766-782, jul./set. 2014 